\title{
Increase of pertussis incidence in 2010 to 2012 after 12 years of low circulation in Spain
}

V Sizaire (vsizaire@isciii.es) ${ }^{1,2}$, M Garrido-Estepa ${ }^{1}$, J Masa-Calles ${ }^{1,3}$, M V Martinez de Aragon ${ }^{1,3}$

1. National Centre for Epidemiology, Institute of Health Carlos III, Madrid, Spain

2. European Programme for Intervention Epidemiology Training (EPIET), European Centre for Disease Prevention and Control (ECDC), Stockholm, Sweden

3. CIBER-Epidemiología y Salud Pública (CIBERESP), Institute of Health Carlos III, Madrid, Spain

Citation style for this article:

Sizaire V, Garrido-Estepa M, Masa-Calles J, Martinez de Aragon MV. Increase of pertussis incidence in 2010 to 2012 after 12 years of low circulation in Spain. Euro Surveill. 2014;19(32):pii=20875. Available online: http://www.eurosurveillance.org/ViewArticle.aspx?Articleld=20875

Article submitted on 08 May 2013 / published on 14 August 2014

In Spain, whole cell pertussis vaccination started in 1975, with three doses before the age of 6-7 months. Doses at 15-18 months and 4-6 years were introduced in 1996 and 2001, respectively. Spain switched to an acellular vaccine in 2005 . From 1998 to 2009, pertussis incidence rates remained $\leq 1.5$ cases/100,000 inhabitants but increased from 2010 to 7.5 cases/100,000 in 2012. Data from 1998 to 2012 were analysed to assess disease trends and susceptible populations. We defined four epidemic periods: 1998-2001 (reference), 2002-05, 2006-09 and 2010-12. In 2002-05, the incidence rate increased in individuals aged 15-49 years (IRR: 1.41 (95\% Cl: 1.11-1.78)) and $\geq 50$ years (IRR: 2.78 (95\% Cl: 1.78-4.33)) and in 2006-09 increased also in infants aged 33 months (IRR: $1.83(95 \% \mathrm{Cl}$ : 1.60-2.09)). In 2010-12, the incidence rate increased notably in all age groups, with IRRs ranging between 2.5 (95\% Cl: 2.3-2.8) in 5-9 year-olds and 36.0 (95\% Cl: $19.4-66.8)$ in 20-29 year-olds. These results, consistent with the country's vaccination history, suggest a progressive accumulation of susceptible individuals due to waning immunity after years of low incidence. Further vaccination strategies should be assessed and implemented to prevent pertussis in pre-vaccinated infants, in whom the disease is more severe.

\section{Introduction}

Pertussis, commonly known as whooping cough, is a highly transmissible respiratory infectious disease caused by Bordetella pertussis. Worldwide, it is estimated that there are 30-50 million pertussis cases and 300,000-400,000 deaths due to the disease per year $[1,2]$. In non-vaccinated populations, pertussis occurs seasonally, with variations in time and place, displaying epidemic cycles of two to five years [3]. The epidemic cycles continue to be observed even when high vaccination coverage ( $\geq 90 \%$ coverage with three doses in infants [4]) is achieved, possibly because pertussis vaccination can protect well against severe forms of disease but not so well against infection [5-8]. Although a dramatic decrease in incidence occurs after the introduction of vaccination against pertussis, elimination of the disease has never been achieved, even in countries with decades of high vaccination coverage $[3,9,10]$.

Recently, a resurgence of the disease has been described in several countries with high vaccine coverage, in North America (the United States [11,12] and Canada [10]) and in Europe (e.g. the Netherlands [13], Norway [14], Germany [15], the United Kingdom [16,17] and Slovenia [18]).

Pertussis resurgence in a context of sustained high vaccination coverage may be explained by the following: (i) better diagnosis and reporting, especially of patients with milder and/or non-specific forms of the disease, in whom notification has been considered underestimated [19]; (ii) waning of natural and vaccineinduced immunity [19]; (iii) loss of vaccine effectiveness due to an antigenic shift of $B$. pertussis strains [13]; and (iv) lower vaccine effectiveness of acellular pertussis vaccine (aP) compared with $\mathrm{WP}[11,20]$ and less sustainable immunity, at least when aP is administered to preschool children (aged $0-6$ years) $[9,21,22]$.

In Spain, the whole cell vaccine against pertussis combined with diphtheria and tetanus toxoids (wP) was commercialised in the 1960 s and administered in two annual campaigns to infants (aged <1 year). In 1975, wP was included in the national childhood immunisation schedule, with three doses (at 3,5 and 7 months of age). In 1996, the vaccination schedule was changed, reducing the age of administration of the three doses, to 2, 4 and 6 months of age, and included an additional fourth dose at 15-18 months of age. In 2001, a fifth dose was added to the vaccination schedule, at 4-6 years of age. In 2005, wP vaccine was replaced by a three-component aP.

Notification by general practitioners of the weekly number of pertussis cases to the national surveillance system has been mandatory in Spain since 1982. In 1996, case-based reporting was implemented, with inclusion of individual basic epidemiological data (sex, age, case classification and history of vaccination) and 
became fully functional in 1998. Pertussis notification remains based on a standard clinical case definition according to criteria of the World Health Organization (WHO) [23] and European Centre for Disease Prevention and Control (ECDC) [24]. A pertussis case was defined as any person with cough lasting at least two weeks, in the absence of another apparent cause, with at least one of the following symptoms: paroxysms of coughing, inspiratory stridor or convulsive post-tussive vomiting. Cases were classified as: (i) suspected - i.e. a person with clinical criteria; (ii) confirmed by an epidemiological link - i.e. a person with clinical criteria and an epidemiological link to a laboratory-confirmed case; and (iii) laboratory confirmed - isolation of $B$. pertussis from a clinical specimen or $B$. pertussis nucleic acid detected by polymerase chain reaction (PCR) or $B$. pertussis-specific antibody response.

Vaccination coverage in Spain increased progressively during 1982 to 2012 and since 1998 has remained above $95 \%$ for the three basic doses [25]. Vaccination coverage for the four-dose schedule has been between $93 \%$ and $95 \%$ since 1996 , and for the five-dose schedule has remained around $80-90 \%$ since 2001 [25].

After 12 years of low incidence (between 0.8 and 1.5 per 100,000 inhabitants annually from 1998 to 2009 [26]) except for a peak in 2000 , when the rate increased to 2.3/100,000, reported data showed an increase of pertussis incidence during 2010 to 2012 (from 1.9 to 7.5 per 100,000 inhabitants annually). We present here results of pertussis epidemiology in Spain from 1998 to 2012 , to describe incidence overall and by age and hospitalisation trends and to identify the susceptible age groups most affected by the increased incidence. This should help to understand the resurgence of the disease in a context of sustained high vaccination coverage in Europe and provide health authorities with information that will help to define the best vaccination policies.

\section{Methods}

To analyse the general trend of pertussis incidence in Spain in parallel with three-dose vaccine coverage, data on incident cases were obtained from the National Epidemiological Surveillance Network, from 1982 to 1997 as weekly aggregated data and from 1998 onwards as case-based data and data on vaccine coverage for the three-doses schedule were obtained from the Ministry of Health, Social Services and Equality [27]. Since fully functioning case-base notification in 1998, cases without information on age were attributed to the different age groups, assuming a similar distribution by age group for cases with known age in the same year, although from 2005 onwards, only $0.4 \%$ of cases $(40 / 9,960)$ were reported without age information.

Hospitalisation data since 1998 , including patient age and length of stay, were available from the national registry of hospitalisations of the Ministry of Health.
The cause of hospitalisation was considered to be pertussis when the ninth International classification of diseases [28] code 033 was recorded by the hospital as the main diagnosis. Data on mortality due to pertussis were obtained from the national mortality registry of the National Institute of Statistics, as were annual population data, used as denominator. Data on national vaccination coverage within the Spanish national immunisation programme since 1982 were available from the Ministry of Health [27].

We included all notified cases reported to the National Epidemiological Surveillance Network in our analysis, including suspected cases, in order to analyse the overall changes in pertussis incidence. Suspected cases were included because the proportion of cases confirmed by the laboratory or an epidemiological link remained constant during our study period (1998-2012).

We describe here the overall annual pertussis incidence rates, number of deaths due to pertussis and annual hospitalisation rates due to pertussis from 1998 to 2012. To analyse the evolution of the incidence by age, we calculated the annual incidence rates and hospitalisation rate by age group $(<1,1-4,5-9,10-14$, $15-49$ and $\geq 50$ years) from 1998 to 2012 . We also assessed changes in incidence in subgroups of notified cases aged less than 1 year $(\langle 1,1,2,3-5,6-8$ and 9-11 months).

We defined four periods according to the observed epidemic waves and changes in pertussis vaccination: 1998-2001 (reference period), 2002-05 (following introduction of fifth dose of WP at 4-6 years of age), 2006-09 (following switch to aP for all five vaccine doses) and 2010-12 (pertussis resurgence wave), in order to identify possible changes in pertussis epidemiology related to vaccination changes. Period incidence rate ratios (IRRs) and hospitalisation rate ratios (HRRs) were calculated by Poisson regression, taking the 1998-2001 epidemic wave as reference, and expressed as the ratio between the period rates (overall or by age group) and the rate for 1998-2001 in the same group. IRRs or HRRs $>1$ ( $p<0.05$ ) were considered as statistically significant increases in the rate and IRRs or HRRs $<1$ ( $p<0.05$ ) as significant decreases. Confidence intervals were calculated using a Poisson distribution. All statistical analyses were performed using Stata version 12.

\section{Results}

\section{Pertussis annual incidence rates and hospitalisation rates}

Annual vaccination coverage (for the three-dose schedule) and pertussis incidence rates and pertussis hospitalisation rates from 1998 to 2012 are shown, along with those from 1982 to 1997 (Figure 1), 1982 being the start of mandatory notification. 


\section{FIGURE 1}

Pertussis incidence rates, hospitalisation rates and vaccine coverage, Spain, 1982-2012

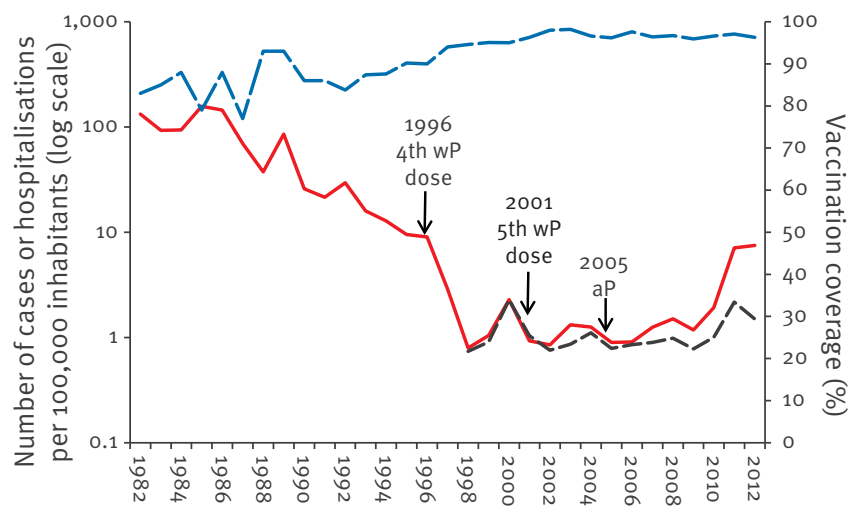

Year

- Number of cases per 100,000 inhabitants

- - Coverage of three vaccine doses before aged 1 year (\%)

- Number of hospitalisations per 100,000 inhabitants

aP: acellular vaccine against pertussis combined with diphtheria and tetanus toxoids. wP; whole cell vaccine against pertussis combined with diphtheria and tetanus toxoids.

Source: Centre for Epidemiology, Institute of Health Carlos III.

Hospitalisations and vaccine coverage: Ministry of Health, Social Services and Equality.
Cases: National Epidemiological Surveillance Network: National

hospitalisation rate: 1.10 ; p<0.001), but after 2006, the increases in incidence rates were higher than those in hospitalisation rates (incidence rate/hospitalisation rate: $2.60 ; p<0.001)$.

\section{Pertussis incidence rates by age group}

The increase in pertussis incidence seen during 2010 to 2012 affected all age groups. From 1998 to 2012, incidence rates increased from 33.4/100,000 in infants (aged 11 year) in 1998 to $177.7 / 100,000$ in 2012, with a peak of $214.0 / 100,000$ in 2011; from 5.6 to 39.0 cases/100,000 children aged $1-4$ years; from 2.3 to 21.2 cases/100,000 children aged 5-9 years; from 2.3 to $19.3 / 100,000$ children aged 10-14 years; and from $0.04-2.27 / 100,000$ individuals aged $\geq 15$ years (Figure 2).

Among infants, a similar increasing trend was observed in all ages, but was particularly clear in children aged $\langle 1,1$ and 2 months of age, i.e. children too young to be vaccinated. Between 1998 and 2012, the incidence increased from 14.5 to $706.1 / 100,000$ infants aged «1 month; from 121.3 to $391.8 / 100,000$ infants aged 1 month; from 86.6 to $422.6 / 100,000$ infants aged 2 months; from 24.4 to $140.4 / 100,000$ infants aged $3-5$ months; from 14.8 to $30.6 / 100,000$ infants aged $6-8$ months; and from 20.5 to $24.6 / 100,000$ infants aged 9-11 months (Figure 3).

Pertussis hospitalisation rates by age group From 1998 to 2009, the annual rate of pertussis hospitalisation tended to decrease in all age groups, except in infants aged \& 1 year, in whom it remained essentially stable (Figure 4), but after 2009, an

\section{FIGURE 2}

Pertussis annual incidence rates by age group, Spain, 1998-2012

From 1982 to 1997 , the mean annual incidence was 58.9 cases/100,000 inhabitants (standard deviation (SD): 13.1). From 1998 to 2009 , except for a peak in 2000 (2.3/100,000), the incidence remained between 0.79 and 1.5 cases/100,000. However, after 2009, the incidence started to increase, with 1.92 cases/100,000 in 2010 and reached 7.5 cases/100,000 in 2012.

The mean pertussis hospitalisation rate during the study period was 1.11/100,000 inhabitants (SD: 0.14), ranging between 0.74 and 2.28/100,000. Similar to incidence rates, after a peak observed in 2000 $(2.28 / 100,000)$, the rate remained between 0.9 and $1.5 / 100,000$ until 2009, when it began to increase, reaching another peak in 2011 (2.2/100,000), with a lower rate in $2012(1.5 / 100,000)$.

Although the hospitalisation and incidence rates followed the same pattern from 1998 to 2012, the incidence rates were slightly higher than the hospitalisation rates between 1998 and 2006 (incidence rate/

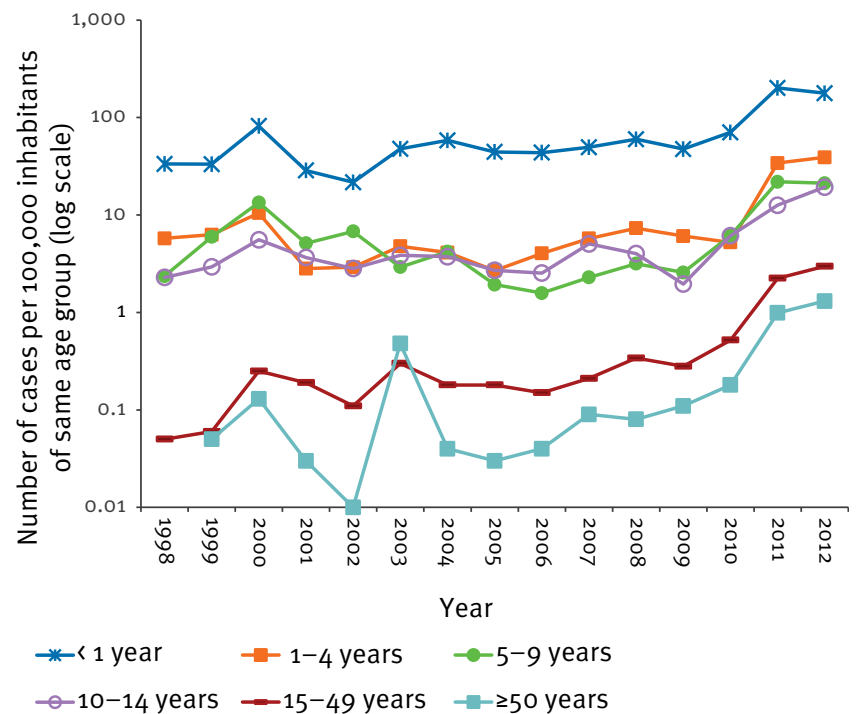

Source: National Epidemiological Surveillance Network. 


\section{FIGURE 3}

Pertussis annual incidence rates in infants aged $<1$ year by age subgroup, Spain, 1998-2012

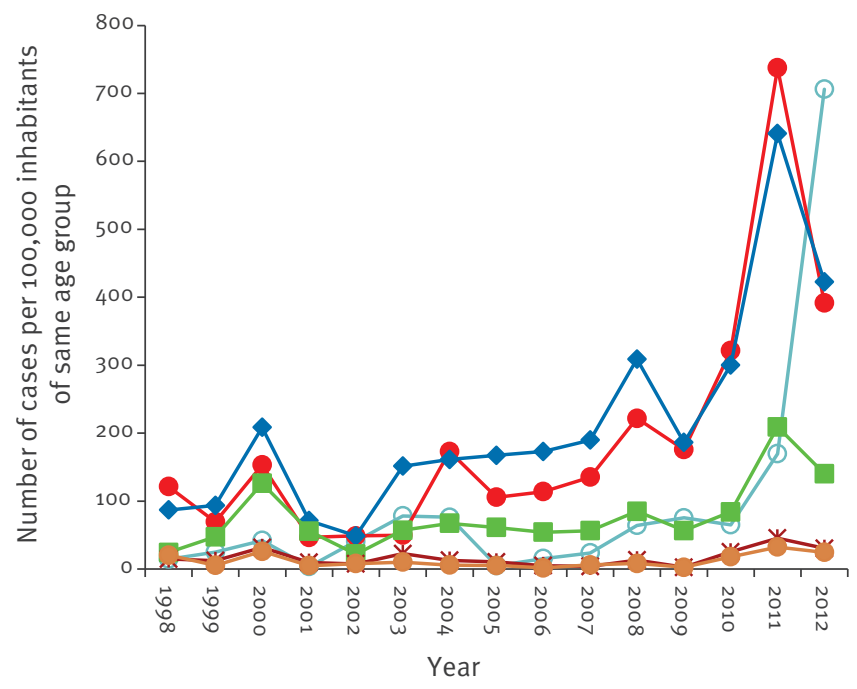

$\begin{array}{ll}-<\text { month } & -1 \text { month } \rightarrow-2 \text { months } \\ --3-5 \text { months } & * 6-8 \text { months } \rightarrow-9-11 \text { months }\end{array}$

Source: National Epidemiological Surveillance Network.

increase was observed in infants aged « 1 year, with a peak in 2011 of 378 hospitalisations/100,000 infants. In 2012, the hospitalisation rate decreased to 131.4 hospitalisations/100,000.

Among infants, annual pertussis hospitalisation rates peaked in 2000 and showed no clear changes in the rates until 2010, when rates started to increase, especially in infants of 1 month of age (in 2011, 923.0/100,000), followed by that in those aged 2 months (in 2011, 658.5/100,000) and «1 month (in 2011, 218.8/100,000) (Figure 5). However in 2012, the hospitalisation rate decreased in these age subgroups (625.3, 434.2/100,000 and 143.7 , respectively).

Pertussis incidence and hospitalisation rate ratios during the epidemic waves

Taking the 1998-2001 epidemic wave as the reference period, we evaluated changes in the incidence and hospitalisation rate ratios in the three successive epidemic waves in 2002-05, 2006-09 and 2010-12 (Tables 1 and 2).

The overall IRR of the disease was «1 during 2002-05 and 2006-09 (p<0.001). In 2010-12, the overall IRR was 4.3 (p<0.001). The overall HRR followed the same pattern as the IRR, with a HRR $<1$ during 2002-05 and 2006-09; in 2010-12, it was 1.2 (p<0.001) (Table 1).
Pertussis incidence and hospitalisation rate ratios by age group

During 2002 to 2005, children aged 1-4 years (IRR: 0.58 , p <0.001) and 5-9 years (IRR: 0.59, p<0.001) showed a significant decrease in the incidence rate (compared with the reference period). In infants aged under < 1 year and children aged between 10-14 years, there was a decrease in the incidence rate, but this was not statistically significant. However, individuals aged $\geq 15$ years had a higher incidence rate, when compared with 1998 to 2001. During 2002 to 2005, the hospitalisation rate decreased in those aged < 1 year , $1-4$ years and especially in the 5-9 year-olds, for whom rates of hospitalisation were reduced nearly by $80 \%$, while those aged over 9 years had a higher rate of hospitalisation (Table 1 ).

In 2006 to 2009, after the switch to aP, the overall IRR was similar to that of the previous epidemic wave (2002-05). In children aged 5-9 years and in adults $\geq 50$ years-old, the IRR was lower than in the preceding wave, while in infants aged «1 year, children aged 1-4 years and individuals aged 15-49 years, the IRR increased. On the other hand, the HRR for all age groups was lower than that in 2002-2005, except for infants aged under 11 year, in whom the HRR remained similar to that of the previous wave (Table 1).

In 2010 to 2012, an increase in incidence was seen in all age groups: the IRR varied between 2.5 and 5.7 in the age groups between 0 and 19 years; in individuals aged 15-49 years, the IRR was 14 and 17 in adults aged $\geq 50$ years. During 2010 to 2012 , in contrast to IRRs,

\section{FIGURE 4}

Pertussis hopitalisation rates per 100,000 inhabitants by age group, Spain, 1998-2012

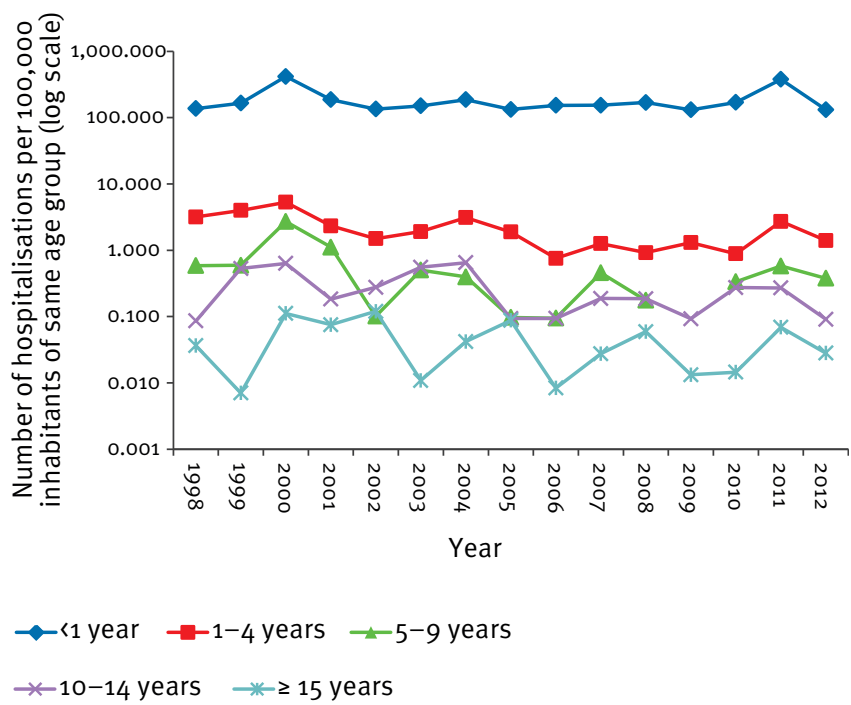

Source: National Epidemiological Surveillance Network. 


\section{FIGURE 5}

Pertussis hopitalisation rates in infants aged $<1$ year by age subgroup, Spain, 1998-2012

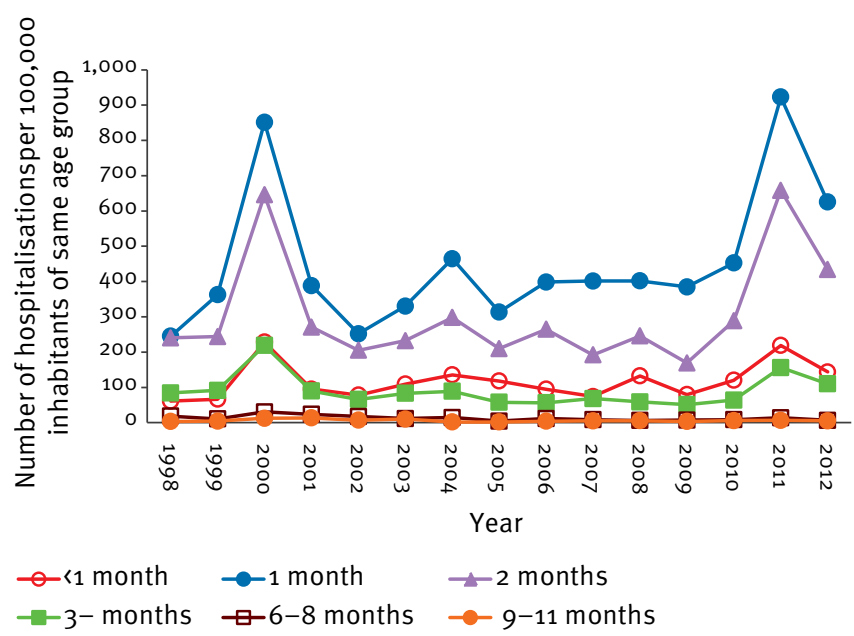

Source: National Epidemiological Surveillance Network.

HRRs remained below 1 (p<0.05) in the age groups 1-4, 5-9 and 10-14 years, whereas the HRR was $>1$ in the age groups 11 year (HRR: 1.16), 15-49 years (HRR: 1.92) and $\geq 50$ years (HRR: 1.24 ) (Table 1 ).

Among infants, a statistically significant IRR of $>1$ (p<0.001) in 2002-05 was seen only in those aged $<1$ month; in 2006-09, the IRR was $>1$ (p<0.001) in those at age of pre-vaccination ( $(1,1$ and 2 months). In 201012 , the IRR was $>1$ for all age subgroups; this was particularly pronounced in those aged $<1$ month (IRR: 14.8, pro.001) (Table 2). Overall, the HRR was $<1$ in 2002-05 and 2006-09 and although it became $>1$ (p<0.001) in 2010-12 (Table 1), this increase affected only infants who had yet not completed the first three doses (i.e. those aged 33 months; IRR: 1.83 (95\% Cl: 1.60-2.09)), $73 \%(1,556 / 2,136)$ of all hospitalisations between 2010 and 2012 .

\section{Duration of hospital stay}

Data from the national registry of hospitalisations showed that the mean hospitalisation stay was 7.9 days (SD: 10.2) for all cases from 1998 to 2012. The length of stay was longer (p<0.001) in infants aged 13 months (mean: 8.7; SD: 11.9 ) than in those aged 3-11 months (mean: $6.5 ; \mathrm{SD}: 5.5$ ) and in individuals $\geq 1$ year of age (mean: 5.7 ; SD: 4.77 ).

A significant (p<0.001) decrease in stay was observed over time: in 1998 to 2001, the mean duration of stay was 8.9 days (SD: 7.7) while in 2010-12, it was 6.8 days (SD: 6.1)

Pertussis-related mortality from 1982 to 2012 Data from the national mortality registry of the National Institute of Statistics showed that from 1982 to 1987, between one and four deaths due to pertussis were observed every year. From 1988 to 1996, there were no pertussis-related deaths, but in 1997, pertussis-related deaths reappeared and increased from 1-2 to 3-5 annual deaths between 2007 and 2010. In 2011, there were eight pertussis-related deaths and six in 2012. Since 1997, all deaths but one (in a person aged 41 years) were reported in infants younger than 3 months.

\section{Discussion}

Our results show that in Spain, pertussis incidence decreased from 133.2/100,000 in 1982 to $0.79 / 100,000$ inhabitants in 1998 after reaching high vaccination

\section{TABLE 1}

Pertussis incidence and hospitalisation rate ratios by age group, Spain, 2002-12

\begin{tabular}{|c|c|c|c|c|c|c|}
\hline \multirow{2}{*}{$\begin{array}{l}\text { Age group } \\
\text { in years }\end{array}$} & \multicolumn{3}{|c|}{ Incidence rate ratio ${ }^{a}(95 \% \mathrm{Cl})$} & \multicolumn{3}{|c|}{ Hospitalisation rate ratio ${ }^{\mathrm{a}, \mathrm{b}}(95 \% \mathrm{Cl})$} \\
\hline & $2002-05$ & $2006-09$ & $2010-12$ & $2002-05$ & $2006-09$ & $2010-12$ \\
\hline$\ll 1$ & $0.98(0.88-1.08)$ & $1.13(1.03-1.25)$ & $3.35(3.07-3.65)$ & $0.70(0.65-0.75)$ & $0.68(0.63-0.72)$ & $1.16(1.09-1.23)$ \\
\hline $1-4$ & $0.58(0.49-0.68)$ & $0.92(0.80-1.06)$ & $4.25(3.79-4.75)$ & $0.60(0.45-0.81)$ & $0.29(0.20-0.41)$ & $0.56(0.41-0.76)$ \\
\hline $5-9$ & $0.59(0.51-0.68)$ & $0.36(0.31-0.42)$ & $2.51(2.27-2.79)$ & $0.23(0.13-0.44)$ & $0.14(0.07-0.30)$ & $0.44(0.26-0.73)$ \\
\hline $10-14$ & $0.91(0.78-1.07)$ & $0.94(0.80-1.10)$ & $3.60(3.16-4.10)$ & $1.43(0.75-2.72)$ & $0.39(0.15-1.01)$ & $0.67(0.28-1.57)$ \\
\hline $15^{-19}$ & $0.63(0.38-1.03)$ & $1.38(0.92-2.07)$ & $5.65(4.03-7.92)$ & \multirow{4}{*}{-} & \multirow{4}{*}{ - } & \multirow{4}{*}{-} \\
\hline $20-29$ & $4.81(2.48-9.35)$ & $4.82(2.47-9.38)$ & $36.03(19.42-66.84)$ & & & \\
\hline $30-39$ & $1.19(0.80-1.77)$ & $1.54(1.06-1.77)$ & $13.16(9.63-17.98)$ & & & \\
\hline $40-49$ & $1.87(1.09-3.20)$ & $1.91(1.12-3.23)$ & $21.47(13.64-33.81)$ & & & \\
\hline $15-49$ & $1.41(1.11-1.78)$ & $1.77(1.42-2.21)$ & $14.06(11.63-16.99)$ & $1.76(0.70-4.42)$ & $1.03(0.37-2.84)$ & $1.92(0.75-4.96)$ \\
\hline$\geq 50$ & $2.78(1.78-4.33)$ & $1.57(0.97-2.53)$ & $16.91(11.40-25.09)$ & $1.01(0.47-2.14)$ & $0.53(0.22-1.28)$ & $1.24(0.59-2.62)$ \\
\hline Total & $0.86(0.80-0.91)$ & $0.81(0.76-0.86)$ & $4.34(4.13-4 \cdot 55)$ & $0.75(0.70-0.80)$ & $0.72(0.67-0.77)$ & $1.23(1.16-1.31)$ \\
\hline
\end{tabular}

a The reference period was 1998 to 2001.

${ }^{b}$ Hospitalisation rate ratios were not calculated for the age groups $15-19,20-29,30-39$ and $40-49$ years, as the number of hospitalisations in these groups was small. Instead, these age groups were combined, with the hospitalisation rate ratio calculated for individuals aged $15-49$ years.

Source: National Epidemiological Surveillance Network. 
TABLE 2

Pertussis incidence and hospitalisation rate ratios in infants aged under 1 year, by age subgroup, Spain, 2002-12

\begin{tabular}{|c|c|c|c|c|c|c|}
\hline \multirow{2}{*}{$\begin{array}{l}\text { Age group } \\
\text { in months }\end{array}$} & \multicolumn{3}{|c|}{ Incidence rate ratio ${ }^{a}(95 \% \mathrm{Cl})$} & \multicolumn{3}{|c|}{ Hospitalisation rate ratio ${ }^{a}(95 \% \mathrm{Cl})$} \\
\hline & $2002-05$ & $2006-09$ & $2010-12$ & $2002-05$ & 2006-09 & $2010-12$ \\
\hline$\ll 1$ & $2.38(1.54-3.67)$ & $2.17(1.41-3.34)$ & $14.78(10.08-21.68)$ & $0.98(0.79-1.22)$ & $0.83(0.67-1.04)$ & $1.32(1.07-1.63)$ \\
\hline 1 & $1.00(0.79-1.27)$ & $1.65(1.33-2.04)$ & $4.68(3.85-5.68)$ & $0.75(0.66-0.84)$ & $0.85(0.76-0.96)$ & $1.38(1.24-1.54)$ \\
\hline 2 & $1.18(0.96-1.46)$ & $1.54(1.27-1.87)$ & $3.45(2.88-4.13)$ & $0.67(0.59-0.77)$ & $0.64(0.56-0.73)$ & $1.23(1.10-1.40)$ \\
\hline $3-5$ & $0.83(0.70-0.99)$ & $0.88\left(0.75^{-1.04}\right)$ & $2.07(1.78-2.40)$ & $0.61(0.53-0.70)$ & $0.49(0.42-0.57)$ & $0.89(0.78-1.02)$ \\
\hline $6-8$ & $0.80(0.56-1.13)$ & $0.30(0.19-0.47)$ & $1.82(1.34-2.46)$ & $0.58(0.41-0.83)$ & $0.42(0.29-0.62)$ & $0.48(0.32-0.71)$ \\
\hline $9-11$ & $0.51(0.33-0.79)$ & $0.26(0.15-0.44)$ & $1.57(1.12-2.21)$ & $0.60(0.35-1.04)$ & $0.54(0.32-0.93)$ & $0.65(0.37-1.14)$ \\
\hline
\end{tabular}

a The reference period was 1998 to 2001.

Source: National Epidemiological Surveillance Network.

coverage against pertussis, and remained around 1.0/100,000, with a cyclical pattern of epidemic waves every three to five years as described in the literature [3]. However, after 12 years with an incidence $\leq 1.5 / 100,000$ (except for a peak of 2.3/100,000 inhabitants in 2000), there was a significant increase that started in 2010, with 1.92 cases/100,000 and reached $7.5 / 100,000$ in 2012, affecting especially individuals $>14$ years and infants 33 months of age. Other countries in North America and Europe with consolidated high vaccination coverage have observed similar re-emergence of pertussis $[10,13-18,29]$.

The PCR method, introduced during the mid-1990s, was already widely used by all laboratories and hospitals in Spain by the 2000s. If better diagnosis and increased notification have played a role in the increased incidence, it would probably be due to increased awareness among clinicians. However, the fact that the proportion of cases confirmed by the laboratory or an epidemiological link has remained constant over time, the increase in pertussis-related deaths since 2007 and the different trends by age group compatible with the history of vaccination in Spain observed in our results suggest a real increase in pertussis incidence. As would be expected from the vaccination history, in 2002-05 there was already a decrease in incidence and pertussis-related hospitalisation in infants aged $>2$ months. We also observed a decrease in incidence in children of 1-4 and 5-9 years of age - more evident in those aged 5-9 years - after the introduction of the fourth and fifth doses in 1996 and 2001. However, in the last period of our study (2010-12), these age groups presented a marked increased incidence as well.

During 1998 to 2012, the highest reported pertussis incidence was observed among infants « 1 year-old. However, looking at the trends by age group, reported pertussis incidence started increasing first among individuals aged $>19$ years during 2002-05, while children aged between 3 months and 19 years continued to be protected. During the last period of our study (2010-2012), although reported incidence increased significantly in all age groups, the most important increase was observed in those aged $\geq 15$ years. This may be explained not only by better diagnosis and improved reporting but also by the progressive accumulation of susceptible individuals, including unvaccinated people who were born before there was high vaccination coverage, and loss of population immunity (natural or acquired by vaccination), after years of low incidence, which reduced the opportunities for boosting immunity with the natural disease [30].

Immunity is known to wane in around 7-20 years after pertussis infection and 5-6 years after immunisation [30]. Regarding post-vaccine waning immunity, among children aged 10-14 years, the increase of pertussis incidence started only in the last period of our study (2010-12) and was less than that observed among the $\geq 15$ year-olds, in contrast to reports from other countries in Europe, where the increase in pertussis incidence has been seen more in the 10-14 years age group [31]. In our study, lower incidence in this age group (compared with that seen in those aged $\geq 15$ years) is probably associated with the fifth-dose effect at the age of $4-6$ years.

In addition to those aged $\geq 15$ years, the other group affected by an increase in pertussis incidence during 2006-09 were infants, specifically those too young to have received the first three doses of pertussis vaccine. This can be explained as a consequence of the infants being infected at home by siblings, parents or grandparents [32]. The important increase in pertussis incidence, hospitalisation and mortality among infants is consistent with ongoing transmission of $B$. pertussis in Spain, independent of a possible increase in notification during the last period of our study.

The most recent change in the vaccine calendar was the switch from whole cell to acellular vaccine in 2005 . Although aP causes fewer side effects than wP [12], it has been suggested that it has reduced effectiveness compared with WP $[11,20]$. Moreover, protection of $\mathrm{aP}$ does not last as long as that of wP $[11,22,33]$. 
Consistent with the characteristics of aP, our data suggest an increasing incidence rate in children born after the switch from WP to aP in 2005 (during 2006-09 compared with 2002-05). This was shown by the fact that the incidence rate started increasing in those aged 1-4 years, already in 2006-09, while in those aged 5-9 years, who had received the five WP doses, the incidence rate was still decreasing. In the subsequent period of our study (2010-12), the IRR became significantly higher in this after-2005 birth cohort, which included both the 1-4 and the 5-9 year-old children. This is also compatible with our observations that in infants not yet vaccinated, both incidence and hospitalisation rates increased while in vaccinated infants and children, the incidence increased in the last period but the hospitalisation rates continued to decrease, because the vaccine would protect more against severe disease than against infection itself [1]. Consistent with that, we also found a reduction in duration of hospitalisation stay over the study period, which may be associated with the occurrence of less severe forms of the disease. Specific studies will be needed in order to verify these results and estimate vaccine effectiveness.

The main limitations of our study were firstly that the vaccination status of the diagnosed patients was not included in the analysis. However, as pertussis vaccination coverage has remained above $95 \%$ since 1998 for the three basic doses, vaccination coverage for the four-dose schedule has been between $93 \%$ and $95 \%$ since 1996, and although coverage for the five-dose schedule has remained around $80-90 \%$ since 2001, we can assume that the ratio of vaccinated to non-vaccinated pertussis cases remained constant throughout the study period. However, during 2010 to 2012, a notable increase in incidence was seen even in younger age groups with constant vaccination coverage.

Secondly, only some diagnosed patients were laboratory confirmed. However, the proportion of laboratoryconfirmed cases remained stable since 2005 , so we do not consider that the increased incidence was a result of increased laboratory confirmation. Additionally, because laboratory-confirmed cases are more comparable with hospitalised cases, inclusion of all cases in our study allowed us to describe changes in the overall pertussis incidence rate and this probably would be biased if using only laboratory-confirmed cases had been included.

In conclusion, the last epidemic wave of pertussis seen in 2010-12 shows an increasing trend of the disease, with its main public health consequences affecting pre-vaccinated infants. This will require further reinforcement of pertussis surveillance in Spain, with an emphasis on infants, and assessment of other targeted vaccination strategies, such as cocooning, consisting of selective immunisation of mothers and close family contacts of newborns, as in Switzerland [34] and a maternal vaccination strategy, consisting of administering pertussis vaccine during pregnancy, as proposed in
England [35] and Canada [36] in order to prevent infection in infants. Neonatal immunisation has also been suggested, but the effectiveness of one dose in newborns has been questioned given the possible interference with maternal antibodies and the vulnerability of newborns [37]. Discussions about different strategies are being carried out at national level by the Spanish Inter-territorial Health Council. However, to date, only specific recommendations for outbreak situations have been adopted [31].

\section{Acknowledgements}

The authors would like to thank all the epidemiologists and health officers who have participated in pertussis surveillance in the National Epidemiological Surveillance Network.

\section{Conflict of interest}

None declared.

\section{Authors' contributions}

Vinciane Sizaire: data analysis and writing as main author M. Garrido Estepa: support for the statistical analysis and reviewer. J. Masa Calles: revised drafts. MV Martínez de Aragon: mentoring and writing.

\section{References}

1. Centers for Disease Control and Prevention (CDC). Pertussis (whooping cough). Atlanta, GA: CDC. Updated 11 Jun 2012. [Accesssed 10 Apr 2013]. Available from: http://www.cdc.gov/ pertussis/countries.html

2. Crowcroft NS, Stein C, Duclos P, Birmingham M. How best to estimate the global burden of pertussis? Lancet Infect Dis. 2003;3(7):413-8. http://dx.doi.org/10.1016/ S1473-3099(03)00669-8

3. Crowcroft NS, Pebody RG. Recent developments in pertussis. Lancet. 2006;367(9526):1926-36. http://dx.doi.org/10.1016/ S0140-6736(06)68848-X

4. Pertussis vaccines: WHO position paper. Wkly Epidemiol Rec. 2010;85(40):385-400.

5. Cherry JD. Historical review of pertussis and the classical vaccine. J Infect Dis. 1996;174 Suppl 3:S259-63. http://dx.doi. org/10.1093/infdis/174.Supplement_3.S259

6. Deville JG, Cherry JD, Christenson PD, Pineda E, Leach CT, Kuhls TL, et al. Frequency of unrecognized Bordetella pertussis infections in adults. Clin Infect Dis. 1995;21(3):639-42. http:// dx.doi.org/10.1093/clinids/21.3.639

7. Gay NJ, Miller E. Pertussis transmission in England and Wales. Lancet. 2000;355(9214):1553-4. http://dx.doi.org/10.1016/ S0140-6736(05)74603-1

8. Schmitt-Grohé S, Cherry JD, Heininger U, Uberall MA, Pineda $\mathrm{E}$, Stehr K. Pertussis in German adults. Clin Infect Dis. 1995;21(4):860-6. http://dx.doi.org/10.1093/clinids/21.4.860

9. Clark TA, Messonnier NE, Hadler SC. Pertussis control: time for something new? Trends Microbiol. 2012;20(5):211-3. http:// dx.doi.org/10.1016/j.tim.2012.03.003

10. Skowronski DM, De Serres G, MacDonald D, Wu W, Shaw C, Macnabb J, et al. The changing age and seasonal profile of pertussis in Canada. J Infect Dis. 2002;185(10):1448-53. http:// dx.doi.org/10.1086/340280

11. Cherry JD. Epidemic pertussis in 2012--the resurgence of a vaccine-preventable disease. N Engl J Med. 2012;367(9):785-7. http://dx.doi.org/10.1056/NEJMp1209051

12. Shapiro ED. Acellular vaccines and resurgence of pertussis. JAMA. 2012;308(20):2149-50. http://dx.doi.org/10.1001/ jama.2012.65031

13. de Melker HE, Schellekens JF, Neppelenbroek SE, Mooi FR, Rümke HC, Conyn-van Spaendonck MA. Reemergence of pertussis in the highly vaccinated population of the 
Netherlands: observations on surveillance data. Emerg Infect Dis. 2000;6(4):348-57. http://dx.doi.org/10.3201/ eido604.000404

14. Lavine JS, Biørnstad ON, de Blasio BF, Storsaeter J. Shortlived immunity against pertussis, age-specific routes of transmission, and the utility of a teenage booster vaccine Vaccine. 2012;30(3):544-51. http://dx.doi.org/10.1016/j. vaccine.2011.11.065

15. Wiese-Posselt $M$, Hellenbrand W. Changes to the varicella and pertussis immunisation schedule in Germany 2009: background, rationale and implementation. Euro Surveill. 2010;15(16): $\mathrm{pii}=19548$.

16. Amirthalingam G, Gupta S, Campbell H. Pertussis immunisation and control in England and Wales, 1957 to 2012: a historical review. Euro Surveill. 2013;18(38): pii=20587.

17. Riolo MA, King AA, Rohani P. Can vaccine legacy explain the British pertussis resurgence? Vaccine. 2013:31(49):5903-8. http://dx.doi.org/10.1016/j.vaccine.2013.09.020

18. Grgic-Vitek M, Klavs I, Kraigher A. Re-emergence of pertussis in Slovenia: time to change immunization policy. Vaccine. 2008;26(15):1874-8. http://dx.doi.org/10.1016/j. vaccine.2008.01.045

19. Gabutti G, Rota MC. Pertussis: a review of disease epidemiology worldwide and in Italy. Int J Environ Res Public Health. 2012;9(12):4626-38. http://dx.doi.org/10.3390/ ijerph9124626

20. Bisgard KM, Rhodes P, Connelly BL, Bi D, Hahn C, Patrick $\mathrm{S}$, et al. Pertussis vaccine effectiveness among children 6 to 59 months of age in the United States, 1998-2001. Pediatrics. 2005;116(2):e285-94. http://dx.doi.org/10.1542/ peds.2004-2759

21. Vickers D, Ross AG, Mainar-Jaime RC, Neudorf C, Shah S. Whole-cell and acellular pertussis vaccination programs and rates of pertussis among infants and young children. CMAJ. 2006;175(10):1213-7. http://dx.doi.org/10.1503/cmaj.051637

22. Witt MA, Katz PH, Witt DJ. Unexpectedly limited durability of immunity following acellular pertussis vaccination in preadolescents in a North American outbreak. Clin Infect Dis. 2012;54(12):1730-5. http://dx.doi.org/10.1093/cid/cis287

23. World Health Organization (WHO). WHO-recommended standards for surveillance of selected vaccine-preventable diseases. Geneva: WHO; 2003. Available from: http://apps. who.int/iris/bitstream/10665/68334/1/WHO_V-B_03.01_eng. pdf

24. European Centre for Disease Prevention and Control (ECDC). Pertussis. Stockholm: ECDC. [Accessed 19 Dec 2013]. Available from: http://ecdc.europa.eu/en/activities/surveillance/euvac/ case_definition/Pages/pertusis.aspx

25. Grupo de Trabajo Tos Ferina 2012 de la Ponencia de Programas y Registro de Vacunaciones. Revisión del programa de vacunación frente a tos ferina en Espa-a. [Review of the vaccination programme against pertussis in Spain]. Madrid: Comisión de Salud Pública del Consejo Interterritorial del Sistema Nacional de Salud. Ministerio de Sanidad, Servicios Sociales e Igualdad; 2013. Spanish. Available from: http://www.msssi.gob.es/profesionales/saludPublica/ prevPromocion/vacunaciones/docs/TosFerina.pdf

26. Situación epidemiológica de la tos ferina en Espa-a. [Epidemiological situation of pertussis in Spain]. Madrid: Centro Nacional de Epidemiologia, Insituto de Salud Carlos III, Ministerio de ciencia e innovación; 11 Sep 2012. Spanish.

27. Coberturas de vacunación. Datos estadísticos. [Vaccine coverage. Statistical data]. Updated 30 Apr 2013. Madrid: Ministerio de Sanidad, Servicios Sociales e Igualdad. [Accessed 30 Apr 2013]. Spanish. Available from: https://www. msssi.gob.es/profesionales/saludPublica/prevPromocion/ vacunaciones/coberturas.htm

28. CIE-9-MC. Clasificación Internacional de Enfermedades, $9^{\underline{a}}$ Revisión Modificación Clínica. [International classification of diseases, 9th revision clinical modification]. 8th ed. Madrid: Ministerio de Sanidad, Política Social e Igualdad, Secretaría General Técnica; 2012. Spanish. Available from http://www. msc.es/estadEstudios/estadisticas/docs/CIEgMC_8ed.pdf

29. Güriş D, Strebel PM, Bardenheier B, Brennan M, Tachdjian $\mathrm{R}$, Finch $\mathrm{E}$, et al. Changing epidemiology of pertussis in the United States: increasing reported incidence among adolescents and adults, 1990-1996. Clin Infect Dis. 1999;28(6):1230-7. http://dx.doi.org/10.1086/514776

30. Wendelboe AM, Van Rie A, Salmaso S, Englund JA. Duration of immunity against pertussis after natural infection or vaccination. Pediatr Infect Dis J. 2005;24(5 Suppl):S58-61. http://dx.doi.org/10.1097/01.inf.0000160914.59160.41

31. Zepp F, Heininger U, Mertsola J, Bernatowska E, Guiso N, Roord J, et al. Rationale for pertussis booster vaccination throughout life in Europe. Lancet Infect Dis. 2011;11(7):557-70. http:// dx.doi.org/10.1016/S1473-3099(11)70007-X
32. Wendelboe AM, Njamkepo E, Bourillon A, Floret DD, Gaudelus J, Gerber M, et al. Transmission of Bordetella pertussis to young infants. Pediatr Infect Dis J. 2007;26(4):293-9. http:// dx.doi.org/10.1097/01.inf.0000258699.64164.6d

33. Tartof SY, Lewis M, Kenyon C, White K, Osborn A, Liko J, et al. Waning immunity to pertussis following 5 doses of DTaP. Pediatrics. 2013;131(4):e1047-52. http://dx.doi.org/10.1542/ peds.2012-1928

34. Urwyler $P$, Heininger U. Protecting newborns from pertussis - the challenge of complete cocooning. BMC Infect Dis. 2014;14(1)397. [Epub ahead of print]. http://dx.doi. org/10.1186/1471-2334-14-397

35. Amirthalingam G, Andrews N, Campbell H, Ribeiro S, Kara $\mathrm{E}$, Donegan K, et al. Effectiveness of maternal pertussis vaccination in England: an observational study. Lancet. 2014. pii: So140-6736(14)60686-3.

36. Matlow JN, Pupco A, Bozzo P, Koren G. Tdap vaccination during pregnancy to reduce pertussis infection in young infants. Can Fam Physiscian. 2013;59(5):497-8.

37. Conyn M, van der Maas N, Mooi F. Control of whooping cough in the Netherlands: optimisation of the vaccination policy. Bilthoven: National Institute for Public Health and the Environment (RIVM); 2013. RIVM report $215121002 / 2012$ Synopsis available from: http://www.rivm.nl/en/ Documents and_publications/Scientific/Reports/2013/ februari/Control_of_whooping_cough_in_the_Netherlands Optimisation_of_the_vaccination_policy:181357 